\title{
Investigation on ERCC5 genetic polymorphisms and the development of gastric cancer in a Chinese population
}

\author{
L.Q. Yang ${ }^{1}$, Y. Zhang ${ }^{2}$ and H.F. Sun ${ }^{3}$ \\ ${ }^{1}$ Department of Gastroenterology, \\ The Second Affiliated Hospital of Xi' an Medical University, Xi' an, China \\ ${ }^{2}$ Department of Oncology, Guang'anmen Hospital, \\ China Academy of Chinese Medical Sciences, Beijing, China \\ ${ }^{3}$ Department of Medical Oncology, Shaanxi Provincial Tumor Hospital, \\ Xi'an, China \\ Corresponding author: Y. Zhang \\ E-mail: zhangyingg661@163.com
}

Genet. Mol. Res. 15 (3): gmr.15038364

Received December 29, 2015

Accepted February 11, 2016

Published August 26, 2016

DOI http://dx.doi.org/10.4238/gmr.15038364

Copyright $(C 2016$ The Authors. This is an open-access article distributed under the terms of the Creative Commons Attribution ShareAlike (CC BY-SA) 4.0 License.

\begin{abstract}
Our study aimed to investigate the role of 2 ERCC5 promoter SNPs (rs2094258 and rs751402) in the development of gastric cancer in the Chinese population. The present hospital-based case-control study consisted of 155 patients with gastric cancer and 246 healthy controls recruited between March 2012 and December 2014. Genotyping for the rs2094258 and rs751402 polymorphic sites was carried out using polymerase chain reaction-restriction fragment length polymorphism. Statistical analyses were conducted using the SPASS version 16.0 software (SPSS, Inc., Chicago, IL, USA). As determined by the chi-square test, there was a significant difference in the genotype distributions of rs751402 between patients and controls $\left(\chi^{2}=6.74, \mathrm{P}\right.$
\end{abstract}


$=0.03)$. By unconditional logistic regression analysis, we observed that the TT genotype in rs751402 was significantly associated with increased risk to gastric cancer as compared with the CC genotype, and the adjusted OR $(95 \% \mathrm{CI})$ was 2.17 (1.15-4.09). Moreover, subjects carrying the $\mathrm{T}$ allele in rs751402 had elevated risk of developing gastric cancer when compared with those carrying the $\mathrm{C}$ allele, with an adjusted OR value $(95 \% \mathrm{CI})$ of 1.47 (1.09-1.99). In conclusion, we suggest that the ERCC5 rs751402 gene polymorphism may influence the susceptibility to gastric cancer in the Chinese population.

Key words: ERCC5; Polymorphism; Gastric cancer; Chinese population

\section{INTRODUCTION}

Gastric cancer is a highly lethal form of cancer, and it is increasing in incidence worldwide (Shah and Kelsen, 2010). Intensive studies have focused on identification of gastric cancer-related genes (Lynch et al., 2005; Aung et al., 2006; Sun et al., 2013). Many transcription factors, such as caudal-related homeobox family genes, have been demonstrated to participate in gastric cancer tumorigenesis and progression (Sakakura et al., 2005; Li et al., 2009, 2014). However, the molecular pathogenesis of gastric cancer is not fully understood. Therefore, it is necessary to identify novel molecular targets involved in gastric cancer tumorigenesis.

Excision repair cross-complementing rodent repair deficiency, complementation group 5 (ERCC5) plays an important part in the NER pathway. Currently, many epidemiologic studies have reported that genetic polymorphisms in the ERCC5 gene contributes to the development of laryngeal cancer, pancreatic cancer, colorectal cancer, uterine cervical cancer, breast cancer, and lung cancer (Liang et al., 2014; Na et al., 2015; Sun et al., 2015; Zeng et al., 2015; Zhao et al., 2015; Joo et al., 2016). Several studies have investigated the relationship between ERCC5 genetic polymorphisms and development of gastric cancer; however, the results were inconclusive (Hussain et al., 2009; Duan et al., 2012; He et al., 2012; Yang et al., 2012; Deng et al., 2014). In the present study, we investigated 2 promoter SNPs in the ERCC5 gene (rs2094258 and rs751402), and their role in gastric cancer development in the Chinese population.

\section{MATERIAL AND METHODS}

\section{Subjects}

The present hospital-based case-control study consisted of 155 patients with gastric cancer as well as 246 healthy controls. All patients were genetically unrelated Han Chinese individuals. Patients who were newly diagnosed with histopathologically confirmed primary gastric cancer were recruited from the Second Affiliated Hospital of Xi' an Medical University between March 2012 and December 2014. Patients who had primary malignant tumors other than gastric cancer were also excluded from this study.

Control subjects were simultaneously recruited from other clinics, and were confirmed to be without gastric cancer via gastrointestinal endoscopy. All control subjects received health examination, and were confirmed to be without malignant tumor, digestive system disorders, as well as kidney and liver diseases.

Genetics and Molecular Research 15 (3): gmr.15038364 
The mean ages of patients with gastric cancer and control subjects were $62.35 \pm 8.30$ and $55.72 \pm 10.64$ years, respectively. In patients with gastric cancer, $44(28.39 \%)$ subjects were females, $111(71.61 \%)$ were males, $58(37.42 \%)$ were people who smoked, and 66 $(42.58 \%)$ were people who drank. In the control subjects, 114 (46.34\%) were females, 132 $(53.66 \%)$ were males, $80(32.52 \%)$ were smokers, and 95 (38.62\%) were drinkers.

Information regarding the demographic characteristics of patients and control subjects was obtained from face-to-face interviews using structured questionnaires. These demographic information included gender, age, body mass index, alcohol consumption, tobacco smoking, and family history of cancer. The clinical data included classification of tumor node metastasis (TNM) stages. A signed informed consent form was obtained from each participant prior to enrollment. This study was approved by the Ethical Board Committee of the Second Affiliated Hospital of Xi'an Medical University.

\section{DNA isolation and genotyping of ERCC5}

Each participant was asked to provide $5 \mathrm{~mL}$ peripheral venous blood sample, which was stored in ethylenediaminetetraacetic acid (EDTA)-treated tubes at $-20^{\circ} \mathrm{C}$. Genomic DNA was isolated from the blood sample via the QIAamp DNA Blood Mini Kit (QIAGEN, USA). Genotyping for rs2094258 and rs751402 polymorphic sites was carried out using polymerase chain reaction-restriction fragment length polymorphism (PCR-RFLP). The forward and reverse primers for rs2094258 and rs751402 polymorphisms were designed using the Sequenom Assay Design 3.1 software (San Diego, CA, USA). PCR was carried out as follows: $95^{\circ} \mathrm{C}$ for $2 \mathrm{~min}$, followed by 35 cycles of $94^{\circ} \mathrm{C}$ for $30 \mathrm{~s}, 65^{\circ} \mathrm{C}$ for $30 \mathrm{~s}$ and $72^{\circ} \mathrm{C}$ for $45 \mathrm{~s}$, and a final elongation was carried out at $72^{\circ} \mathrm{C}$ for $7 \mathrm{~min}$. The resulting fragments were analyzed on a $2 \%$ agarose gel stained with ethidium bromide to determine the genotypes at both polymorphic sites.

\section{Statistical analysis}

Categorical data were analyzed via the $\chi^{2}$ test, and continuous variables were analyzed using Student $t$-tests. The $\chi^{2}$ test was also used to evaluate whether gene frequencies departed from the Hardy-Weinberg equilibrium (HWE) in control subjects, and to compare the differences between cases/controls or subgroups of categorical variables. To estimate the relationship between rs2094258 and rs751402 genetic polymorphisms and the development of gastric cancer, logistic regression analysis was carried out to calculate the adjusted odds ratio (OR) along with $95 \%$ confidence intervals (CI). Statistical analyses were conducted using the SPASS version 16.0 software (SPSS, Inc., Chicago, IL, USA). $\mathrm{P}<0.05$ was considered to be of statistical significant difference.

\section{RESULTS}

We found that patients with gastric cancer were comparable with control subjects in terms of body mass index $(t=1.09, \mathrm{P}=0.14)$, alcohol consumption $\left(\chi^{2}=0.62, \mathrm{P}=0.43\right)$, tobacco smoking $\left(\chi^{2}=1.01, \mathrm{P}=0.32\right)$, and family history of cancer $\left(\chi^{2}=1.51, \mathrm{P}=0.22\right)$ (Table 1). Interestingly, as indicated by $\chi^{2}$ tests and $t$-tests, we found a significant difference between patients and controls in terms of mean age $(t=6.59, \mathrm{P}<0.001)$ and gender $(t=12.84, \mathrm{P}<0.001)$.

Genetics and Molecular Research 15 (3): gmr.15038364 
Table 1. Demographic characteristics of study subjects.

\begin{tabular}{|c|c|c|c|c|c|c|}
\hline Variables & Patients $(\mathrm{N}=155)$ & $\%$ & Controls $(\mathrm{N}=246)$ & $\%$ & $\chi^{2}$ or $t$-tests & $\mathrm{P}$ value \\
\hline Mean age (years) & \multicolumn{2}{|l|}{$62.35 \pm 8.30$} & \multicolumn{2}{|l|}{$55.72 \pm 10.64$} & 6.59 & $<0.001$ \\
\hline \multicolumn{7}{|l|}{ Gender } \\
\hline Female & 44 & 28.39 & 114 & 46.34 & & \\
\hline Male & 111 & 71.61 & 132 & 53.66 & 12.84 & $<0.001$ \\
\hline Body mass index $\left(\mathrm{kg} / \mathrm{m}^{2}\right)$ & \multicolumn{2}{|l|}{$24.56 \pm 3.64$} & \multicolumn{2}{|l|}{$24.15 \pm 3.71$} & 1.09 & 0.14 \\
\hline \multicolumn{7}{|l|}{ Alcohol consumption } \\
\hline No & 89 & 57.42 & 151 & 61.38 & & \\
\hline Yes & 66 & 42.58 & 95 & 38.62 & 0.62 & 0.43 \\
\hline \multicolumn{7}{|l|}{ Tobacco smoking } \\
\hline No & 97 & 62.58 & 166 & 67.48 & & \\
\hline Yes & 58 & 37.42 & 80 & 32.52 & 1.01 & 0.32 \\
\hline \multicolumn{7}{|l|}{ Family history of cancer } \\
\hline No & 142 & 91.61 & 233 & 94.72 & & \\
\hline Yes & 13 & 8.39 & 13 & 5.28 & 1.51 & 0.22 \\
\hline \multicolumn{7}{|l|}{ TNM stage } \\
\hline I-II & 92 & 59.35 & & & & \\
\hline III-IV & 63 & 40.65 & & & & \\
\hline
\end{tabular}

The genotype distributions of rs2094258 and rs751402 between patients with gastric cancer and controls are shown in Table 2. In patients, 71 (45.81\%), 74 (47.74\%), and $10(6.45 \%)$ carried the GG, GA, and AA genotypes, respectively; 49 (31.61\%), 73 $(47.10 \%)$, and $33(21.29 \%)$ carried the CC, CT, and TT genotypes, respectively. Using the $\chi^{2}$ test, we found a significant difference in the genotype distributions of rs751402 between patients and controls $\left(\chi^{2}=6.74, \mathrm{P}=0.03\right)$, but no significant difference was observed in the genotype frequencies of rs 2094258 between the 2 study groups $\left(\chi^{2}=0.46\right.$, $\mathrm{P}=0.79)$. Genotype frequencies of rs 2094258 and $\mathrm{rs} 751402$ were at HWE in both the patients and the controls.

Table 2. Genotype distributions of rs2094258 and rs751402 in patients with gastric cancer and controls.

\begin{tabular}{l|c|c|c|c|c|c|c|c}
\hline SNPs & Patients $(\mathrm{N}=155)$ & $\%$ & Controls $(\mathrm{N}=246)$ & $\%$ & $\chi^{2}$ test & P value & \multicolumn{2}{|c}{ P for HWE } \\
\cline { 5 - 8 } & & & & & & & & \\
\hline rs2094258 & & & & & & & & \\
\hline GG & 71 & 45.81 & 121 & 49.19 & & & & \\
\hline GA & 74 & 47.74 & 111 & 45.12 & & & & \\
\hline AA & 10 & 6.45 & 14 & 5.69 & 0.46 & 0.79 & 0.11 & 0.08 \\
\hline rs751402 & & & & & & & & \\
\hline CC & 49 & 31.61 & 103 & 41.87 & & & & \\
\hline CT & 73 & 47.10 & 111 & 45.12 & & & & \\
\hline TT & 33 & 21.29 & 32 & 13.01 & 6.74 & 0.03 & 0.55 & 0.81 \\
\hline
\end{tabular}

As analyzed by unconditional logistic regression analysis, we observed that individuals carrying the TT genotype in rs751402 showed increased risk to gastric cancer as compared with those carrying the CC genotype; the adjusted OR $(95 \% \mathrm{CI})$ was 2.17 (1.15-4.09) (Table 3 ). Moreover, subjects carrying the $\mathrm{T}$ allele at rs 751402 had an elevated risk of developing gastric cancer as compared with those carrying the $\mathrm{C}$ allele; the adjusted $\mathrm{OR}(95 \% \mathrm{CI})$ was 1.47 (1.09-1.99). However, no significant difference was observed between the rs2094258 gene polymorphism and gastric cancer risk.

Genetics and Molecular Research 15 (3): gmr.15038364 
Table 3. Relationship between rs2094258 and rs751402 genotype polymorphisms and gastric cancer risk.

\begin{tabular}{|c|c|c|c|c|c|c|}
\hline SNPs & Patients $(\mathrm{N}=155)$ & $\%$ & Controls $(\mathrm{N}=246)$ & $\%$ & OR $(95 \% \mathrm{CI})^{1}$ & P value \\
\hline \multicolumn{7}{|c|}{ rs2094258 } \\
\hline GG & 71 & 45.81 & 121 & 49.19 & 1.0 (Ref.) & - \\
\hline GA & 74 & 47.74 & 111 & 45.12 & $1.14(0.73-1.76)$ & 0.55 \\
\hline AA & 10 & 6.45 & 14 & 5.69 & $1.22(0.46-3.12)$ & 0.66 \\
\hline \multicolumn{7}{|l|}{ Allele } \\
\hline G & 216 & 139.35 & 353 & 143.50 & 1.0 (Ref.) & - \\
\hline A & 94 & 60.65 & 139 & 56.50 & $1.11(0.80-1.53)$ & 0.53 \\
\hline \multicolumn{7}{|c|}{ rs751402 } \\
\hline $\mathrm{CC}$ & 49 & 31.61 & 103 & 41.87 & 1.0 (Ref.) & - \\
\hline $\mathrm{CT}$ & 73 & 47.10 & 111 & 45.12 & $1.38(0.86-2.23)$ & 0.16 \\
\hline TT & 33 & 21.29 & 32 & 13.01 & $2.17(1.15-4.09)$ & 0.01 \\
\hline \multicolumn{7}{|l|}{ Allele } \\
\hline $\mathrm{C}$ & 171 & 110.32 & 317 & 128.86 & 1.0 (Ref.) & - \\
\hline $\mathrm{T}$ & 139 & 89.68 & 175 & 71.14 & $1.47(1.09-1.99)$ & 0.01 \\
\hline
\end{tabular}

${ }^{1}$ Adjusted for age and gender.

\section{DISCUSSION}

In this study, we assessed the relationship between ERCC5 rs2094258 and rs751402 polymorphisms and gastric cancer risk in a Chinese population. We observed that the TT genotype and the T allele of rs751402 are associated with an increased risk of gastric cancer in the Chinese population.

The regulation of DNA repair is an important factor in cancer pathology, and the ERCC5 gene is a crucial part of the DNA repair machinery. Previous studies have reported on the association between ERCC5 genetic polymorphisms and development of laryngeal cancer, pancreatic cancer, colorectal cancer, breast cancer, and brain cancer (Lu et al., 2014; Na et al., 2015; Sun et al., 2015; Zhao et al., 2015; Geng et al., 2016; Wang et al., 2016). Na et al. (2015) conducted a study with 325 breast cancer patients and 325 control subjects of Chinese descent, and reported that ERCC 5 rs2094258 may contribute to breast cancer susceptibility. In addition, Wang et al. (2016) revealed that rs 751402 polymorphism may also influence susceptibility to breast cancer in the Chinese Han population. Similarly, Lu et al. (2014) indicated that ERCC5 rs 17655 polymorphism could influence the risk to laryngeal cancer. On the other hand, several other studies suggested that ERCC5 polymorphism is not associated with risk to cancers (Sun et al., 2015; Zhao et al., 2015; Geng et al., 2016).

The relationship between ERCC5 genetic polymorphisms and gastric cancer development has been investigated in several studies, but the results are inconsistent (Hussain et al., 2009; Duan et al., 2012; He et al., 2012; Yang et al., 2012; Deng et al., 2014). Hussain et al. (2009) revealed that rs 751402 polymorphism was correlated with increased risk to gastric cancer in the Chinese population. Duan et al. (2012) also indicated that ERCC5 polymorphisms may alter the risk of developing gastric cancer, especially of the diffuse subtype. Similarly, Yang et al. (2012) reported that rs2094258 and rs2296147 polymorphisms may contribute to the risk of gastric cancer. He et al. (2012) conducted a case-control study with 1125 patients with gastric cancer and 1196 cancer-free controls, and reported that functional ERCC5 variants may contribute to the risk of gastric cancer. In our study, we observed that rs751402 genetic polymorphism plays an important role in the development of gastric cancer. The inconsistent results between studies may be due to differences in patient ethnicities, selection of study subjects, and sample sizes. 
In conclusion, we suggest that the ERCC5 rs751402 gene polymorphism could influence gastric cancer susceptibility in the Chinese population. Further studies are needed to confirm the results of our findings.

\section{Conflicts of interest}

The authors declare no conflict of interest.

\section{REFERENCES}

Aung PP, Oue N, Mitani Y, Nakayama H, et al. (2006). Systematic search for gastric cancer-specific genes based on SAGE data: melanoma inhibitory activity and matrix metalloproteinase-10 are novel prognostic factors in patients with gastric cancer. Oncogene 25: 2546-2557. http://dx.doi.org/10.1038/sj.onc.1209279

Deng N, Liu JW, Sun LP, Xu Q, et al. (2014). Expression of XPG protein in the development, progression and prognosis of gastric cancer. PLoS One 9: e108704.http://dx.doi.org/10.1371/journal.pone.0108704

Duan Z, He C, Gong Y, Li P, et al. (2012). Promoter polymorphisms in DNA repair gene ERCC5 and susceptibility to gastric cancer in Chinese. Gene 511: 274-279. http://dx.doi.org/10.1016/j.gene.2012.09.025

Geng P, Ou J, Li J, Liao Y, et al. (2016). A comprehensive analysis of influence ERCC polymorphisms confer on the development of brain tumors. Mol. Neurobiol. 53: 2705-2714.

He J, Qiu LX, Wang MY, Hua RX, et al. (2012). Polymorphisms in the XPG gene and risk of gastric cancer in Chinese populations. Hum. Genet. 131: 1235-1244. http://dx.doi.org/10.1007/s00439-012-1152-8

Hussain SK, Mu LN, Cai L, Chang SC, et al. (2009). Genetic variation in immune regulation and DNA repair pathways and stomach cancer in China. Cancer Epidemiol. Biomarkers Prev. 18: 2304-2309. http://dx.doi.org/10.1158/10559965.EPI-09-0233

Joo J, Yoon KA, Hayashi T, Kong SY, et al. (2016). Nucleotide excision repair gene ERCC2 and 5 variants increase risk of uterine cervical cancer. Cancer Res. Treat. 48: 708-714.

Li Q, Zhang N, Jia Z, Le X, et al. (2009). Critical role and regulation of transcription factor FoxM1 in human gastric cancer angiogenesis and progression. Cancer Res. 69: 3501-3509. http://dx.doi.org/10.1158/0008-5472.CAN-08-3045

Li T, Lu YY, Zhao XD, Guo HQ, et al. (2014). MicroRNA-296-5p increases proliferation in gastric cancer through repression of Caudal-related homeobox 1. Oncogene 33: 783-793. http://dx.doi.org/10.1038/onc.2012.637

Liang Y, Deng J, Xiong Y, Wang S, et al. (2014). Genetic association between ERCC5 rs17655 polymorphism and lung cancer risk: evidence based on a meta-analysis. Tumour Biol. 35: 5613-5618. http://dx.doi.org/10.1007/s13277-014$\underline{1742-2}$

Lu B, Li J, Gao Q, Yu W, et al. (2014). Laryngeal cancer risk and common single nucleotide polymorphisms in nucleotide excision repair pathway genes ERCC1, ERCC2, ERCC3, ERCC4, ERCC5 and XPA. Gene 542: 64-68. http://dx.doi. org/10.1016/j.gene.2014.02.043

Lynch HT, Grady W, Suriano G and Huntsman D (2005). Gastric cancer: new genetic developments. J. Surg. Oncol. 90 : 114-133, discussion 133. http://dx.doi.org/10.1002/jso.20214

Na N, Dun E, Ren L and Li G (2015). Association between ERCC5 gene polymorphisms and breast cancer risk. Int. J. Clin. Exp. Pathol. 8: 3192-3197.

Sakakura C, Hagiwara A, Miyagawa K, Nakashima S, et al. (2005). Frequent downregulation of the runt domain transcription factors RUNX1, RUNX3 and their cofactor CBFB in gastric cancer. Int. J. Cancer 113: 221-228. http:// dx.doi.org/10.1002/ijc.20551

Shah MA and Kelsen DP (2010). Gastric cancer: a primer on the epidemiology and biology of the disease and an overview of the medical management of advanced disease. J. Natl. Compr. Canc. Netw. 8: 437-447.

Sun W, Wu Y, Yu X, Liu Y, et al. (2013). Decreased expression of long noncoding RNA AC096655.1-002 in gastric cancer and its clinical significance. Tumour Biol. 34: 2697-2701.http://dx.doi.org/10.1007/s13277-013-0821-0

Sun Y, Tan L, Li H, Qin X, et al. (2015). Association of NER pathway gene polymorphisms with susceptibility to laryngeal cancer in a Chinese population. Int. J. Clin. Exp. Pathol. 8: 11615-11621.

Wang H, Wang T, Guo H, Zhu G, et al. (2016). Association analysis of ERCC5 gene polymorphisms with risk of breast cancer in Han women of northwest China. Breast Cancer. 23: 479-485.

Yang WG, Zhang SF, Chen JW, Li L, et al. (2012). SNPs of excision repair cross complementing group 5 and gastric cancer risk in Chinese populations. Asian Pac. J. Cancer Prev. 13: 6269-6272. http://dx.doi.org/10.7314/ APJCP.2012.13.12.6269

Genetics and Molecular Research 15 (3): gmr.15038364 
Zeng Y, Wei L, Wang YJ and Liu C (2015). Genetic association between ERCC5 rs17655 polymorphism and colorectal cancer risk: evidence based on a meta-analysis. Asian Pac. J. Cancer Prev. 16: 5565-5571. http://dx.doi.org/10.7314/ APJCP.2015.16.13.5565

Zhao F, Shang Y, Zeng C, Gao D, et al. (2015). Association of single nucleotide polymorphisms of DNA repair genes in NER pathway and susceptibility to pancreatic cancer. Int. J. Clin. Exp. Pathol. 8: 11579-11586.

Genetics and Molecular Research 15 (3): gmr.15038364 